\title{
Multielement trace determination in high purity advanced ceramics and high purity metals
}

\author{
R MATSCHAT*, H-J HEINRICH, M CZERWENSKY, S KUXENKO and H KIPPHARDT \\ Federal Institute for Materials Research and Testing (BAM), D-12200 Berlin, Germany
}

\begin{abstract}
In the field of advanced ceramics two CRMs were developed in the last few years by the Federal Institute for Materials Research and Testing, one for silicon nitride and one for silicon carbide. Besides their application by industry they are appropriate to be used for the validation of special methods used for trace determination in accordance with high purity materials. This is demonstrated, for example, on ultrapure silicon carbide which was analysed by solid sampling electrothermal atomic absorption spectrometry (SS ET AAS).

BAM is also certifying primary pure reference materials used as the National Standards for inorganic analysis in Germany. The crucial point of this project is the certification of the total purity of high purity materials, each representing one element of the periodic table. A variety of different analytical methods was necessary to determine the trace contents of metallic and non-metallic impurities from almost the whole periodic table in the high purity materials. The primary CRMs of copper, iron and molybdenum are used as examples to demonstrate the modus operandi, analytical effects observed by using high resolution ICP mass spectrometry (HR ICP-MS) and the results.
\end{abstract}

Keywords. Advanced ceramics; pure metals; SS ET AAS; HR ICP-MS.

\section{Introduction}

Certified reference materials (CRMs) are very important in chemical analysis for validating analytical procedures and checking trueness of results as well as for establishing traceability of the results to the SI units, as described by Meyer and Matschat (2000).

In several cases each kind of chemical digestion applied to very pure advanced ceramics causes blank values much too high and intolerable in view of achieving trustable analytical results. In these cases direct solid sampling methods can be applied advantageously. However, these methods need a validated calibration by appropriate solid substances or, if possible, by solutions. Therefore, we investigated the analytical capabilities of solid sampling electrothermal atomic absorption spectrometry (SS ET AAS) applied to the determination of trace elements in high purity advanced ceramics. The application of SS ET AAS has been described together with the method of inductively coupled plasma optical emission spectrometry with electrothermal evaporation (ETV ICP OES) used for slurries and solid samples, in detail, by Kurfurst (1998). We had used and compared both methods and had applied them to the analysis of tungsten metal powder in the past (see Matschat et al 2003). The multielement capability of ETV ICP OES was much higher, but the limits of determination were lower with SS ET AAS than with ETV ICP OES. In our present work, we investigated the possibilities to calibrate SS ET AAS by using aque-

*Author for correspondence (ralf.matschat@bam.de) ous solutions. To check the trueness of results of this kind of analysis, certified reference materials (CRMs) of the same material are needed. Introductorily the certification of two CRMs, powders of silicon nitride and a silicon carbide, respectively, is described in this paper. The chemical digestion of silicon carbide is more difficult, therefore, it was used as material for further studies.

Another focal point discussed in this paper is the characterization of primary high purity substances certified as National Standards for elemental analysis. These materials are of high importance to establish a traceability chain to the SI unit of an analytical result achieved by an elemental analytical method which needs to be calibrated. The uncertainty of the mass fraction of main component of this primary pure material contributes to the final analytical result. We decided to aim at $0.01 \%$ as target value for the uncertainty of mass fraction of the primary pure materials. Such a very low uncertainty cannot be attained by using a method for direct determination of the main component. Hence all possible trace elements must be quantitatively determined and the sum of all mass fractions has to be subtracted from $100 \%$. In this paper some aspects of the certification of three materials $(\mathrm{Cu}, \mathrm{Fe}$, $\mathrm{Mo}$ ) as examples of the already certified $10 \mathrm{CRMs}(\mathrm{Bi}$, $\mathrm{Cu}, \mathrm{Ga}, \mathrm{Fe}, \mathrm{Pb}, \mathrm{Si}, \mathrm{Sn}, \mathrm{W}, \mathrm{NaCl}, \mathrm{KCl}$ ) are discussed.

\section{Advanced ceramics}

The growing application of advanced ceramic materials in many areas of modern materials research and development, in manufacturing engineering, in high temperature 
applications as well as in medicine and in microelectronics is explained by their unique properties.

\subsection{Certification of silicon nitride}

Silicon nitride powder is a starting material for the production of advanced ceramic materials particularly used with regard to high temperature applications. The silicon nitride quality LC10 (H.C. Starck company, Germany) was used as the candidate material for CRM. In connection with the certification two interlaboratory comparisons were organized in which 46 experienced laboratories from 13 countries participated. In table 1 the certified values are listed (including their uncertainties) for this European Reference Material (ERM $\left.{ }^{\circledR}\right)$, certified by BAM.

A typical example of the certification of trace elements in this CRM is illustrated in figure 1. It shows the distribution of results as delivered from international partner laboratories.

As often is the case, also in this case the other participants, delivered results of only one analytical method. In BAM additional methods were used to avoid the potentially unnoticed systematic deviations of this single method that could influence the final result.

Even a very fast microwave high pressure digestion of the silicon nitride powder, as described by Matschat et al
(1999), is rather time consuming. Therefore, and because of the blank values caused by the acids used, it will be of advantage to apply direct solid sampling methods, especially in case of the analysis of materials of highest purity. The use of slurry-sampling ET AAS was described by Friese and Krivan (1995). Very low limits of detection in the magnitude of some $\mathrm{ng} / \mathrm{g}$ could be achieved for some analytes.

\subsection{Certification of silicon carbide}

In the early field of application, $\mathrm{SiC}$ was used as abrading medium. Today $\mathrm{SiC}$ is of additional wide technical importance because of its outstanding properties useful for opto- and micro-electronic applications. Especially in view of this application, trace element contents and other chemical parameters are of eminent importance. They must be determined on the metrologically solid basis of a CRM, as it was developed at BAM. The silicon carbide powder candidate material (quality green micro F800) was taken from a customary production line (Wacker Ceramics, Kempten, Germany). The interlaboratory comparison for certification was carried out by 29 participants from 8 different countries. Results are listed in table 2 . The evaluation of the results of a typical analyte $(\mathrm{Cr})$ is illustrated in figure 2 .

Table 1. Certified values of the "ERM ${ }^{\circledR}-E D 101$ silicon nitride powder" ( $w=$ mass fraction in $(* \mathrm{mg} / \mathrm{kg})$ or $(* * \%), U=$ expanded uncertainty $(k=2), \beta * * *=\beta$ phase $)$.

\begin{tabular}{|c|c|c|c|c|c|c|c|c|c|c|}
\hline Parameter & $\mathrm{Al}^{*}$ & $\mathrm{Ca}^{*}$ & $\mathrm{Co}^{*}$ & $\mathrm{Fe}^{*}$ & $\mathrm{Mg}$ * & $\mathrm{Na}^{*}$ & $\mathrm{~W}^{*}$ & $\mathrm{C}^{* *}$ & $\mathrm{~N}^{* *}$ & $\beta * * *$ \\
\hline$w$ & 469 & $14 \cdot 1$ & $43 \cdot 5$ & $79 \cdot 5$ & $4 \cdot 3$ & $7 \cdot 59$ & $41 \cdot 3$ & $0 \cdot 162$ & $38 \cdot 1$ & $7 \cdot 43$ \\
\hline$U$ & 12 & 0.5 & $0 \cdot 8$ & 13 & $0 \cdot 4$ & $0 \cdot 27$ & $1 \cdot 3$ & $0 \cdot 024$ & $0 \cdot 2$ & $0 \cdot 09$ \\
\hline
\end{tabular}

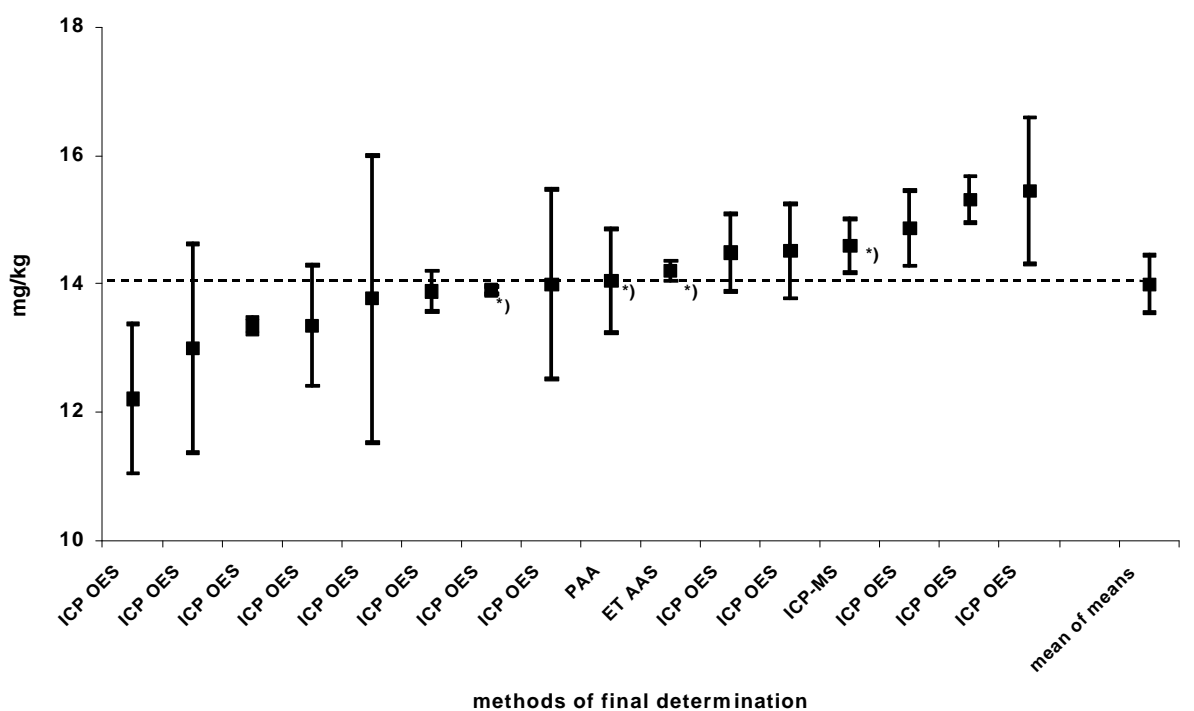

Figure 1. Certification of the analyte Ca in $\mathrm{ERM}^{\circledR}-\mathrm{ED} 101$ silicon nitride powder; BAM results are marked by an asterisk (ordinate $=$ mass fraction). 


\subsection{Investigations on silicon carbide by SS ET AAS}

The chemical digestion of silicon carbide powder by strong acids at high pressure and temperature is very time consuming. High purity silicon carbide powders, especially with a larger grain size, are difficult to analyse, because the total digestion can require to use highest concentrated fluoric acid and because intolerable high blanks can occur. In view of these drawbacks direct solid sampling techniques offer advantages. Our investigations were based on research carried out by Schaffer and Krivan (2001). They investigated the analysis of high purity graphite and silicon carbide by SS ET AAS. We used an improved version of the AAS spectrometer. It was the ZEEnit 60 combined with the automatic solid sampling system SSA 61Z from Analytik Jena AG, Germany. In all cases pyrolytically coated graphite tubes and sample boats were used, which were cleaned by a heating-up step at $2500-2700^{\circ} \mathrm{C}$. The analytical parameters were optimized for the analytes $\mathrm{Ca}, \mathrm{Cr}, \mathrm{Cu}, \mathrm{Fe}, \mathrm{Mg}, \mathrm{Mn}$, $\mathrm{Na}$ and $\mathrm{Ni}$. Aluminum had been excluded from the list of analytes after severe difficulties were found to determine its mass fraction accurately. The drying temperature was $180^{\circ} \mathrm{C}$, the pyrolysis temperature was adjusted, depending on the analyte between 800 and $1200^{\circ} \mathrm{C}$ using a heating rate of $100 \mathrm{~K} / \mathrm{s}$. The atomization temperature was set depending on the analyte in the range between $2100^{\circ} \mathrm{C}$ (for $\mathrm{Mg}$ ) and $2600^{\circ} \mathrm{C}$ (for $\mathrm{Ca}, \mathrm{Cr}$ and $\mathrm{Ni}$ ) using heating rates of 1000-1200 K/s. In our investigations we were in the advantageous situation that we could use the well certified CRM "BAM-S003 silicon carbide powder" described above. Not only the certified mass fractions of the analytes in this material were well known, but also the homogeneity of the material had been carefully investigated. Calibration curves achieved by different sample masses of this CRM were systematically compared with calibration curves established with aqueous solutions as displayed in figure 3 .

A good or atleast sufficient agreement between both types of calibration was also found for the other analytes under investigation; all calibration functions were linear or slightly non-linear. Thus a simplified calibration process based on usage of aqueous standards could be validated in case of this analytical problem. By other experiments

Table 2. Certified values of the CRM "BAM-S003 silicon carbide powder" ( $w=$ mass fraction in $(* \mathrm{mg} / \mathrm{kg})$ or $(* * \%), U=$ expanded uncertainty $(k=2))$.

\begin{tabular}{|c|c|c|c|c|c|c|c|c|}
\hline Parameter & $\mathrm{Al}^{*}$ & $\mathrm{~B}^{*}$ & $\mathrm{Ca}^{*}$ & $\mathrm{Cr}^{*}$ & $\mathrm{Cu}^{*}$ & $\mathrm{Fe}^{*}$ & $\mathrm{Mg}^{*}$ & $\mathrm{Mn}^{*}$ \\
\hline$w$ & 372 & 63 & $29 \cdot 4$ & $3 \cdot 5$ & $1 \cdot 5$ & 149 & $6 \cdot 3$ & $1 \cdot 44$ \\
\hline$U$ & 20 & 7 & $1 \cdot 8$ & $0 \cdot 4$ & $0 \cdot 4$ & 10 & 0.6 & $0 \cdot 17$ \\
\hline Parameter & $\mathrm{Na}^{*}$ & $\mathrm{Ni}^{*}$ & $\mathrm{Ti}^{*}$ & $\mathrm{~V}^{*}$ & $\mathrm{Zr}^{*}$ & $\mathrm{C}_{\text {free }} *$ & $\mathrm{O}^{*}$ & $\mathrm{C}_{\text {total }} * *$ \\
\hline$w$ & $17 \cdot 7$ & $32 \cdot 9$ & 79 & $41 \cdot 4$ & $25 \cdot 2$ & 493 & 909 & $29 \cdot 89$ \\
\hline$U$ & $0 \cdot 8$ & $2 \cdot 7$ & 4 & $2 \cdot 8$ & $2 \cdot 0$ & 79 & 35 & $0 \cdot 07$ \\
\hline
\end{tabular}

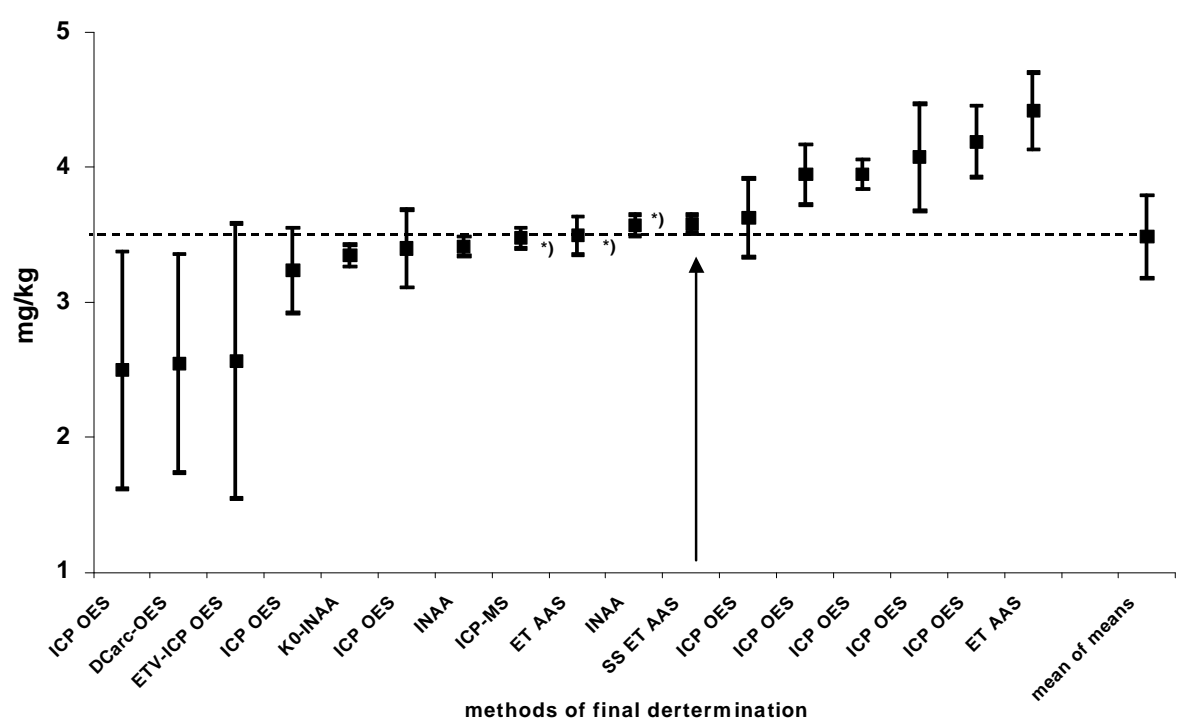

Figure 2. Certification of the analyte $\mathrm{Cr}$ in CRM "BAM-S003 silicon carbide powder"; $\mathrm{BAM}$ results are marked by an asterisk (ordinate = mass fraction). 
it could be demonstrated, that different masses of subsamples have no significant influence on the analytical results. The limits of determination (LODs; $9 s$ criterion) were determined based on 10 measurements of blank values of empty sample boats using maximum sensitivity of measurement according to the method of "zero-mass response" as described by Kurfurst (1998). The results are summarized in table 3.

Very low LODs could be achieved in the order of $1 \mathrm{ng} / \mathrm{g}$ and below. This is a very good basis for the certification of the trace contents in a very pure silicon carbide powder, which is now under investigation. In figure 2 the result which was achieved at the readily certified CRM BAM-S003 using SS ET AAS is marked by an arrow. One can conclude that the result has a very high trueness and precision when comparing the position of the mean value and the extension of the uncertainty interval, respectively, with results of other laboratories and methods. This was further confirmed by the data shown in figure 4 . A good agreement between certified values and results obtained by using SS ET AAS can be concluded.

\section{Primary pure metals}

The importance of primary high purity materials and the fundamental way of how to certify them for their use as National Standards of elemental analysis was briefly described in the introduction. As explained, the uncertainty should not exceed the tenth part of the uncertainty attainable by the best methods in inorganic analysis, i.e. it should not be higher than $0 \cdot 01 \%$. This can be achieved by determining all trace contents and subtracting the sum from $100 \%$. Different analytical methods were used to determine all metallic and non-metallic trace contents as mapped in figure 5. For detailed information see the earlier paper by Matschat et al (2002).

\subsection{Primary pure copper}

The results of certification are compiled in detail in the BAM certification report (Kipphardt 2004). The values of mass fractions of 82 trace elements were determined by analytical measurements either above the limits of deter-

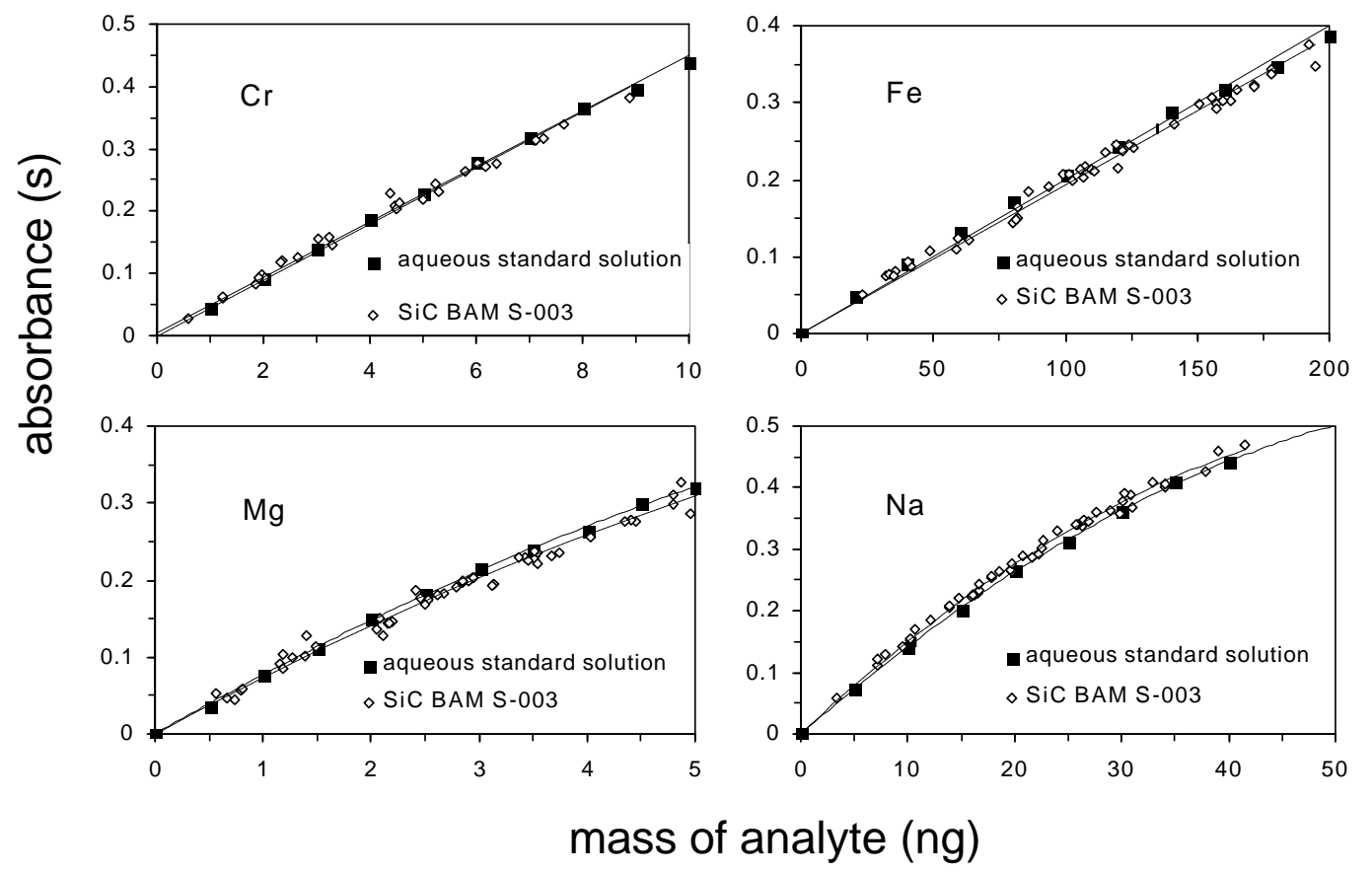

Figure 3. Calibration curves of SS ET AAS for $\mathrm{Cr}, \mathrm{Fe}, \mathrm{Mg}$ and $\mathrm{Na}$, respectively, by using aqueous standard solutions as well as different masses of CRM "BAM-S003 silicon carbide".

Table 3. Limits of determination ( $9 s$ criterion) achieved in the analysis of silicon carbide powder by SS ET AAS (results based on $5 \mathrm{mg}$ sample weight).

\begin{tabular}{lllllllll}
\hline Element & $\mathrm{Ca}$ & $\mathrm{Cr}$ & $\mathrm{Cu}$ & $\mathrm{Fe}$ & $\mathrm{Mg}$ & $\mathrm{Mn}$ & $\mathrm{Na}$ & $\mathrm{Ni}$ \\
\hline Analyte mass (pg) & 2 & 4 & 6 & $7 \cdot 6$ & 0.3 & $2 \cdot 2$ & 0.6 & 7.3 \\
Mass fraction (ng/g) & 0.4 & 0.8 & $1 \cdot 2$ & 1.5 & 0.05 & 0.5 & 0.1 & 1.5 \\
\hline
\end{tabular}


mination (LODs) (18 trace elements) or below "limitvalues" (LVs) (64 trace elements), with LV $\geq$ LOD. The mass fractions of 9 trace elements (most of instable elements) were estimated based on theoretical considerations. The high resolution ICP mass spectrometry (HR ICP-MS), mainly operated in low resolution mode, had delivered most of the results (for 60 trace elements). The certified value of the mass fraction in the BAM-Y001 material is $w(\mathrm{Cu}, \mathrm{BAM}-\mathrm{Y} 001)=(99.9970 \pm 0 \cdot 0010) \%$; expanded uncertainty $U$ with $k=2$. An uncertainty one order of magnitude lower than the aimed value could be achieved.

\subsection{Primary pure iron}

The starting material was a pure iron CRM certified for six analytes by the EURONORM group (EURONORM CRM 098-1). Confirmation of most of the certified

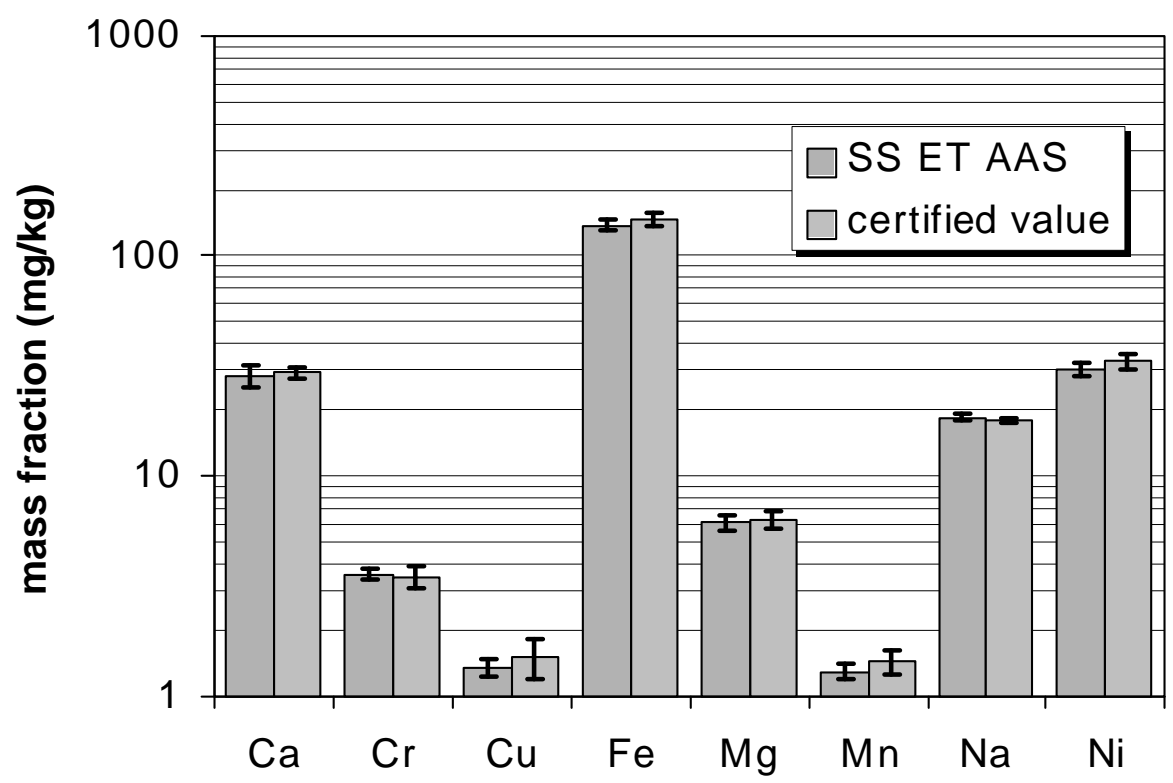

Figure 4. Results obtained from analysis of silicon carbide CRM BAM-S003 by SS ET AAS using aqueous standard solutions (mean \pm SD) in comparison with certified values.

\section{Scheme of certification of ultrapure metals as primary calibration substances (Type A)}

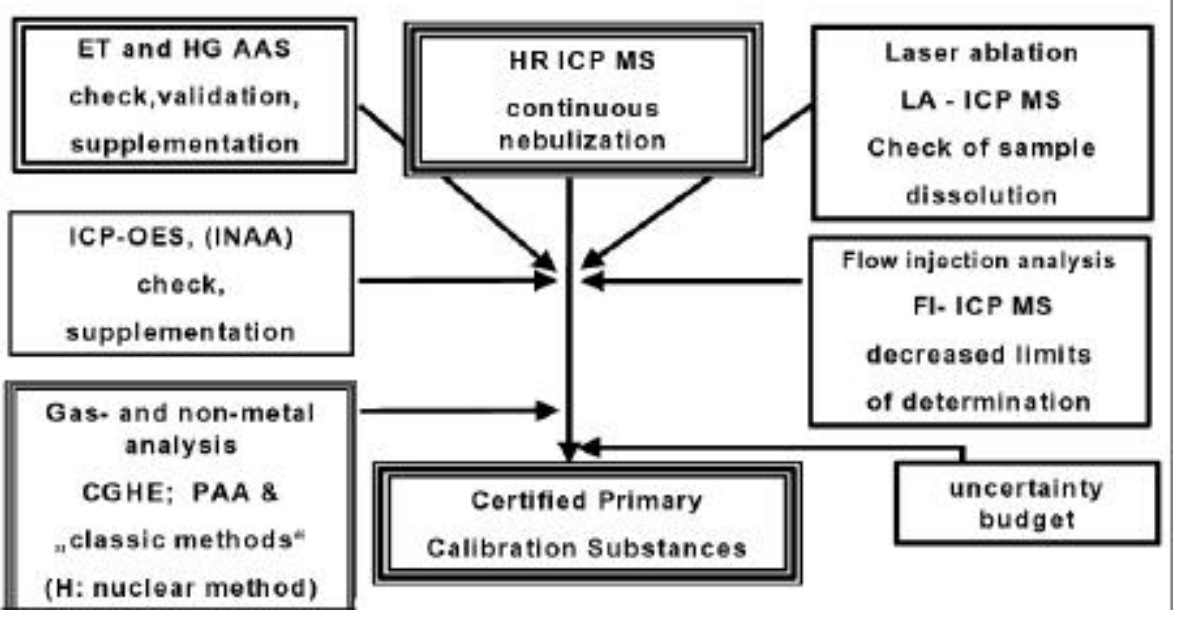

Figure 5. Scheme of the certification of primary pure materials by using different analytical methods. 
values was achieved by own measurements using HR ICP-MS and ET AAS. After this was completed satisfactorily, the certification was carried out in determining the other remaining relevant analytes of the periodic table (> 60 analytes). For this primary pure material a mass fraction was certified: $w(\mathrm{Fe})=(99.986 \pm 0.004) \%(U$ with $k=2$ ). Therefore, one can conclude that by the way of using an existing CRM as a starting material a combined uncertainty for the mass fraction of iron much lower than the target uncertainty can be achieved, too.

\subsection{Primary pure molybdenum}

For some matrices the interference pattern in ICP MS can get very complex. A typical example is the molybdenum matrix (7 isotopes with masses between 92 and 100 and isotopic abundances of $>9 \%$ for all isotopes). Therefore, interfering patterns are observed at lower masses for $\mathrm{Ti}$ (with the doubly charged molybdenum ions), at $\mathrm{m} / \mathrm{z}: 93$ $\left({ }^{92} \mathrm{MoH}^{+}\right)$for $\mathrm{Nb}$, and at many different segments in higher masses for $\mathrm{In}, \mathrm{Cd}, \mathrm{Cs}, \mathrm{Ba}, \mathrm{Ce}, \mathrm{Pr}, \mathrm{Nd}$ and $\mathrm{Dy}$ (with polyatomic ions containing atoms of the matrix and of $\mathrm{H}, \mathrm{O}, \mathrm{N}$ or Ar). Among other things it was demonstrated in detail, how these interferences can be handled, by using higher resolution modes of the ICP mass spectrometer (Matschat et al 2003).

\section{Conclusions}

It can be concluded, that the certification of advanced ceramic reference materials such as silicon nitride or silicon carbide powders is not only of importance for their industrial use but can also be used as a basis for the validation of simplified calibration procedures in solid sampling atomic absorption spectrometry. This was demonstrated using silicon carbide powder as an example. The extremely low limits of detection observed will allow to certify the trace contents in a very pure silicon carbide. The concept developed for the certification of very pure material used as National Standards of elemental analysis can be assessed as very successful. The determination of all relevant traces in the pure material at low levels of contents and subtracting the sum of all traces from $100 \%$ led to very low uncertainties much lower than the target value of $0.01 \%$. Pure matrix CRMs can also be used as starting material for primary pure materials, as was demonstrated using iron as an example. Spectral interferences in ICP mass spectrometry are in some cases very complex as shown for molybdenum. They can partly be overcome by using the appropriate higher mass resolution or adapted evaluation procedures.

\section{Acknowledgements}

The authors would like to express their gratitude and sincere appreciation to A Dette and N Langhammer for their valuable contributions to certify the reference materials.

\section{References}

Friese K-Ch and Krivan V 1995 Anal. Chem. 67354

Kipphardt H 2004 Certification Report, BAM-Y001, BAM, Federal Institute for Materials Research and Testing

Kurfürst U 1998 Solid sample analysis_-Direct and slurry sampling using GF-AAS and ETV-ICP (Berlin, Heidelberg: SpringerVerlag)

Matschat R, Meyer K, Heinrich H-J and Scharf H 1999 Advances in process measurements for the ceramic industry (eds) A Jillavenkatesa and G J Onoda (Westerville, Ohio: The American Ceramic Society) p. 107

Matschat R, Czerwensky M, Pattberg S and Heinrich H-J 2002 Mater. Trans._Jap. Inst. Metals $\mathbf{4 3} 90$

Matschat R, Czerwensky M, Traub H, Heinrich H-J and Kipphardt H 2003 Matériaux \& Techniques $N^{\circ}$ Hors Série, December 2003, 37

Meyer K and Matschat R 2000 in Reference materials in analytical chemistry (ed.) A Zschunke (Heidelberg: Springer Verlag) p. 57

Schäffer U and Krivan V 2001 Fresenius J. Anal. Chem. 371859 